\title{
HIF-1 $\alpha$ regulates A2B adenosine receptor expression in liver cancer cells
}

\author{
JAE HYUN KWON ${ }^{1,2^{*}}$, JOOYOUNG LEE ${ }^{2,3^{*}}$, JIYE KIM ${ }^{2,3}$, YONG HWA JO ${ }^{4}$, VARVARA A. KIRCHNER ${ }^{2,5}$, \\ NAYOUNG KIM ${ }^{3}$, BONG JUN KWAK ${ }^{6}$, SHIN HWANG ${ }^{1,2}$, GI-WON SONG ${ }^{1,2}$, SUNG-GYU LEE ${ }^{1,2}$, \\ YOUNG-IN YOON ${ }^{1,2}$, GIL-CHUN PARK ${ }^{1,2^{*}}$ and EUNYOUNG TAK ${ }^{2,3^{*}}$
}

${ }^{1}$ Division of Liver Transplantation and Hepatobiliary Surgery, Department of Surgery; ${ }^{2}$ Asan-Minnesota Institute for Innovating Transplantation, Asan Institute for Life Sciences; ${ }^{3}$ Department of Convergence Medicine, Asan Medical Institute of Convergence Science and Technology, Asan Medical Center, University of Ulsan College of Medicine, Seoul 05505;

${ }^{4}$ Department of Biochemistry and Molecular Biology, School of Medicine, Kyung Hee University, Seoul 02447 , Republic of Korea; ${ }^{5}$ Division of Transplantation, Department of Surgery and Asan-Minnesota Institute for Innovating Transplantation, University of Minnesota, Minneapolis, MN 55455, USA; ${ }^{6}$ Division of Hepatobiliary-Pancreas Surgery and Liver Transplantation, Department of Surgery, Seoul St Mary's Hospital, College of Medicine,

The Catholic University of Korea, Seoul 06591, Republic of Korea

Received June 26, 2019; Accepted August 19, 2019

DOI: $10.3892 / \mathrm{etm} .2019 .8081$

\begin{abstract}
Liver cancer exhibits the fourth most common cause of cancer-associated mortality worldwide. Due to the rapid growth, solid tumors undergo severe hypoxia and produce high levels of extracellular adenosine to maintain homeostasis. A previous study indicated that the hypoxic condition in liver cancer increased hepatic adenosine, which is known to facilitate cancer survival and proliferation. Extracellular adenosine has been revealed to regulate pathological and physiological processes in cells and tissues. However, its pathophysiological role in liver cancer remains undetermined. Emerging evidence has indicated that the adenosine A2B receptor promotes the progression of liver
\end{abstract}

Correspondence to: Dr Gil-Chun Park, Division of Liver Transplantation and Hepatobiliary Surgery, Department of Surgery, Asan Medical Center, University of Ulsan College of Medicine, 88 Olympic-ro 43-gil, Songpa-gu, Seoul 05505, Republic of Korea E-mail: gcpark@amc.seoul.kr

Dr Eunyoung Tak, Asan-Minnesota Institute for Innovating Transplantation, Asan Institute for Life Sciences, Asan Medical Center, University of Ulsan College of Medicine, 88 Olympic-ro 43-gil, Songpa-gu, Seoul 05505, Republic of Korea

E-mail: eunyoung.tak@amc.seoul.kr

${ }^{*}$ Contributed equally

Abbreviations: HCC, hepatocellular carcinoma; HIF-1 $\alpha$, hypoxia inducible factor-1 $\alpha$; HRE; hypoxia response element; A2B, adenosine $\mathrm{A} 2 \mathrm{~B}$ receptor

Key words: liver cancer, adenosine A2B receptor, hypoxia inducible factor-1 $\alpha$, adenosine, hypoxia cancer. Therefore, it was hypothesized that HIF-1 $\alpha$ is a transcriptional regulator of $\mathrm{A} 2 \mathrm{~B}$ in human liver cancer. The current study determined A2B expression of a number of liver cancer cell lines and performed functional studies of HIF-1 $\alpha$ as a master transcriptional regulator of hepatic A2B signaling during hypoxic conditions. The current study aimed to identify the promoter region of $\mathrm{A} 2 \mathrm{~B}$, which has a hypoxia response element, by performing luciferase assays. The present study demonstrated that reduced HIF-1 $\alpha$ expression is associated with low expression of A2B, and HIF-1 $\alpha$ overexpression is associated with A2B induction. Furthermore, the siRNA-mediated downregulation of A2B inhibited the growth and proliferation of HepG2, which is a liver cancer cell line. The relationship between HIF- $1 \alpha$ and A2B expression was also identified in human liver cancer specimens. In conclusion, the current study indicated that A2B is induced by the HIF-1 $\alpha$ transcriptional regulator during hypoxia, and it may be a potential pharmacologic and therapeutic target for the treatment of patients with liver cancer.

\section{Introduction}

Liver cancer is the fourth leading cause of cancer mortality worldwide $(1,2)$. Despite significant progress over the past decades, the clinical outcomes of patients with liver cancer remain poor and an in-depth understanding of the molecular pathogenesis of liver cancer could facilitate the development of novel diagnostic and therapeutic techniques.

Adenosine is an endogenous nucleoside that controls many physiological processes through interactions with adenosine receptors, such as A1, A2A, A2B, and A3 (3). Adenosine A2 receptors have two segmented isoforms; high-affinity A2A receptor which is highly concentrated in the striatum, and relatively low-affinity A2B receptors which present throughout the brain (4). Generally, adenosines can be found eluted into the 
extracellular matrix of ordinary solid organs under low-oxygen conditions (5). However, in cancerous organs, the signaling pathway generated between adenosine and its receptor has been shown to coordinate adenosine accumulation and the increased levels of adenosine in the extracellular fluid of solid tumors stimulate cancer cell proliferation and tumor angiogenesis (6). The relationship between the tumor progression and adenosine $\mathrm{A} 2 \mathrm{~B}$ receptor expression has been investigated in many types of tumors including bladder (7), breast (8), colon (9), and prostate (10) cancers. While some researchers have shown that $\mathrm{A} 2 \mathrm{~B}$ is highly expressed in cancerous tissues in patients with HCC (11), the regulatory pathways and the function of $\mathrm{A} 2 \mathrm{~B}$ in liver cancer remain undiscovered.

The adenosine $\mathrm{A} 2 \mathrm{~B}$ receptor is reported to be transcriptionally induced by tumor necrosis factor-alpha (TNF- $\alpha$ ) (12), interferon-gamma (IFN- $\gamma$ ) (13), and hypoxia-inducible factor- $1 \alpha$ (HIF-1 $\alpha)(14,15)$. HIF-1 $\alpha$ is an oxygen-regulated subunit of HIF-1, a heterodimeric transcription factor consisting of $\alpha$ - and $\beta$-subunits. Intra-tumoral hypoxia is the major cause of increased HIF-1 activity in human HCC (16), and HIF-1 $\alpha$ protein stabilization in cancer cells leading to the upregulation of multiple HIF-1 target genes that are required for HCC tumor growth, as demonstrated by both genetic and pharmacologic loss-of-function studies (17). HIF-1 $\alpha$ mediated expression of adenosine A2B receptor activations in hypoxia has reported in endothelial cells (15), acute lung injury (18), and breast cancer (19). In addition to this, many researchers suggested that hypoxia is one factor for inducing $\mathrm{A} 2 \mathrm{~B}$ expressions, however, direct HIF- $1 \alpha$ mediated A2B increment during tumor progression, especially in liver cancer has not been investigated yet. Therefore, we designed experiments to verify whether transcriptional regulation pathways control the endogenous hepatic adenosine signaling during a low-oxygen condition of liver cancer cells. Furthermore, we also investigated the potential HIF-1 $\alpha$ binding regions in the A2B promoter genes. We believe our study will contribute to the development of new therapeutic targets to treat liver cancers.

\section{Materials and methods}

Cell culture and hypoxic conditions. We purchased human liver cancer cell lines, including HepG2 (KCLB no. 88065; passage 21), the hepatoblastoma cell line (20), and the hepatocellular carcinoma (HCC) cell lines SK-Hep1 (KCLB no. 30052; passage 49) and SNU-449 (KCLB no. 00449; passage 28) from the Korean Cell Line Bank (KCLB; Seoul, Republic of Korea). HepG2 and SK-Hep1 cells were maintained in Dulbecco's modified Eagle's medium (DMEM) high-glucose (Hyclone; Thermo Fisher Scientific, Inc.), supplemented with $10 \%$ fetal bovine serum (FBS; Mediatech) and $100 \mathrm{U} / \mathrm{ml}$ penicillin/streptomycin (HyClone). The HCC SNU-449 cells were maintained in RPMI-1640 (Invitrogen; Thermo Fisher Scientific, Inc.), supplemented with $10 \%$ FBS and $100 \mathrm{U} / \mathrm{ml}$ penicillin/streptomycin. We cultured all the cells in a standard humidified incubator at $37^{\circ} \mathrm{C}$ in an atmosphere of $5 \% \mathrm{CO}_{2}$. To induce hypoxic conditions, we placed cells in a hypoxia incubator (MCO-18M; Sanyo) filled with a mixture of 5\% $\mathrm{CO}_{2}, 94.5 \% \mathrm{~N}_{2}$, and $0.5 \% \mathrm{O}_{2}$ gas. Authentication of the cell lines was done using short tandem repeat (STR) profiling by the Korean Cell Line Bank (Seoul National University College of Medicine, Seoul, Republic of Korea; http://cellbank.snu. ac.kr/) with proper STR references. The cell lines were tested for mycoplasma contamination before use and were negative for mycoplasma.

Establishment of A2B luciferase constructs. We used a pGL3 basic luciferase vector as a control plasmid and performed luciferase assays with previously designed constructs (15). The full-length construct (1095 bp) had a hypoxia-response element (HRE). The other truncated construct (477 bp) lacked an HRE. Additionally, we used a mutant form of the 1095 bp plasmid with a modified sequence (A $\underline{\mathrm{CGTG}}$ was altered to $\mathrm{A} \underline{\mathrm{ATCG}}$ ).

$A 2 B$ reporter assay. To confirm the transcriptional activity of the adenosine A2B receptor, we used HepG2 cells as an easily transfectable cellular model. First, to investigate the A2B promoter region, we used HepG2 cells to measure the reporter gene activity. We co-transfected cells with $2 \mu \mathrm{g}$ of A2B-Luc promoter-reporter and $0.02 \mu \mathrm{g}$ Renilla reporter vector for $24 \mathrm{~h}$ using Lipofectamine ${ }^{\circledR} 2000$ reagent (Invitrogen; Thermo Fisher Scientific, Inc.), according to the manufacturer's instructions. Next, we exposed the cells to hypoxic conditions for up to $12 \mathrm{~h}$. To prepare whole protein lysates, we used 1x passive lysis buffer (cat no. E1910; Promega). To perform the luciferase assay, we followed the protocol of the Dual-Luciferase Reporter Assay (Promega).

RNA interference. Small interfering RNAs (siRNA) specific to either HIF-1 $\alpha$ (HIF-1 $\alpha$-siRNA), A2B (A2B-siRNA), or scrambled sequences (scr-siRNA) were prepared by Bioneer Corporation. We used $0.5 \mu \mathrm{g}$ of siRNA for transfections using Lipofectamine ${ }^{\circledR} 2000$ reagent (Invitrogen). The sequences of siRNAs were: Scrambled-siRNA (scr-siRNA), sense, 5'-CCU ACGCCACCAAUUUCGU (dTdT)-3', antisense, 5'-ACGAAA UUGGUGGCGUAGG (dTdT)-3'; HIF-1 $\alpha$-siRNA, sense, 5'-GUGGUUGGAUCUAACACUA (dTdT)-3', antisense, 5'-UAGUGUUAGAUCCAACCAC (dTdT)-3'; A2B-siRNA, sense, 5'-GAGACUUCCGCUACACUUU (dTdT)-3', antisense, 5'-AAAGUGUAGCGGAAGUCUC (dTdT)-3'.

HIF-1 $\alpha$ plasmid overexpression. We seeded HepG2 cells into 6-well plates at a density of $1.0 \times 10^{6}$ cells per well and incubated them for $24 \mathrm{~h}$ at $37^{\circ} \mathrm{C}$. The cells were transfected with a HIF-1-pcDNA3.1-expressing plasmid using Lipofectamine ${ }^{\circledR} 2000$ reagent (Invitrogen; Thermo Fisher Scientific, Inc.). We confirmed HIF-1 $\alpha$ overexpression by western blot. The negative control plasmid pcDNA3.1(+) and the HIF-1-pcDNA3.1-expressing plasmids were purchased from Addgene. We treated cells with range from 3 to $300 \mathrm{nM}$ of echinomycin (cat no. 5520; Tocris Bioscience), a specific inhibitor of HIF-1 DNA binding activity, to achieve chemical interference of HIF activity.

BrdU assay. Exponentially growing HepG2 cells were digested, centrifuged, collected, and inoculated into 96-well culture plates at a density of $5.0 \times 10^{3}$ cells/well. After culturing for $24 \mathrm{~h}$ in DMEM containing 10\% FBS, the cells were transfected with scrambled-siRNA (scr-siRNA) and A2B-siRNA. HepG2 cell proliferation activity was analyzed using 
Table I. Clinical characteristic of five patients with HCC in the Asan Medical Center.

\begin{tabular}{|c|c|c|c|c|c|}
\hline Patients & P1 & $\mathrm{P} 2$ & P3 & $\mathrm{P} 4$ & P5 \\
\hline Grading & Grade III & Grade III & Grade III & Grade III & Grade III \\
\hline Gender & $\mathrm{F}$ & M & M & M & $\mathrm{F}$ \\
\hline Age (years) & 38 & 54 & 62 & 65 & 68 \\
\hline Risk Factors & $\mathrm{HBV}$ & $\mathrm{HBV}$ & $\mathrm{HBV}$ & $\mathrm{HBV}$ & $\mathrm{HBV}$ \\
\hline $\operatorname{AST}(\mathrm{U} / \mathrm{l})$ & 174 & 82 & 133 & 191 & 190 \\
\hline $\operatorname{ALT}(\mathrm{U} / \mathrm{l})$ & 128 & 72 & 87 & 147 & 137 \\
\hline Albumin (g/dl) & 3.5 & 3.6 & 3.3 & 3.0 & 2.8 \\
\hline Tumor size $(\mathrm{cm})$ & $3.7 \times 3.3 \times 3.3$ & $2.4 \times 1.5 \times 1.0$ & $4.5 \times 4.0 \times 3.3$ & $11.6 \times 10.8 \times 9.6$ & $14.2 \times 10.8 \times 7$ \\
\hline
\end{tabular}

Tumor size $(\mathrm{cm}) \quad 3.7 \times 3.3 \times 3.3$

$2.4 \times 1.5 \times 1.0$

$4.5 \times 4.0 \times 3.3$

$11.6 \times 10.8 \times 9.6$

$14.2 \times 10.8 \times 7.5$

P, patient; AST, aspartate aminotransferase; ALT, alanine aminotransferase; HBV, hepatitis B virus; HCC, hepatocellular carcinoma.

BrdU cell proliferation assay kits (cat no. 2750; Millipore), $24,48,72$, and $96 \mathrm{~h}$ after siRNA transfection. The BrdU reagent was added to the culture wells at each time point, and the plates were incubated at $37^{\circ} \mathrm{C}$ for an additional $4 \mathrm{~h}$. The cells were then fixed, and the BrdU levels were detected colorimetrically following the manufacturer's instructions. To plot the growth curve, a microplate reader (Sunrise TECAN, Labx, Canada) was used to measure absorbance at $450 \mathrm{~nm}$. Experiments were repeated four times.

Cell growth and viability test. Cell growth and viability were determined by performing a 3-(4,5-dimethythiazol-2-yl)-2,5-diphenyltetrazolium bromide (MTT) assay in 12 well cell culture plates (NEST Biotechnology). HepG2 cells were seeded at a density of $5.0 \times 10^{4}$ per well for $24 \mathrm{~h}$ and cultured in DMEM containing 10\% FBS. The cells were then transfected with scr-siRNA or A2B-siRNA. After incubation for 24,48 , and $72 \mathrm{~h}, 20 \mu \mathrm{l}$ of MTT solution $(5 \mathrm{mg} / \mathrm{ml}$ in phosphate buffer saline) was added to each well, and the plates were incubated in the dark for $4 \mathrm{~h}$ at $37^{\circ} \mathrm{C}$. Cell growth and viability were expressed as the percentage of absorbance of MTT-treated cells relative to that of untreated cells at a wavelength of $540 \mathrm{~nm}$. Measurements for all treatment groups were taken four times.

Patient tissue samples. We collected five individual human HCC specimens from patients with HCC, who visited the Asan Medical Center (Division of Liver Transplantation and Hepatobiliary Surgery; Seoul, Republic of Korea) between 2014 and 2015 (Table I). None of the patients received any form of treatment before surgical procedures. We separately collected small pieces of the tumor and adjacent normal tissues and snap-froze them into liquid nitrogen. Frozen samples were stored at $-80^{\circ} \mathrm{C}$ until use. The Institutional Review Board of Asan Medical Center reviewed and approved the collection and use of patient specimens (approval no. 2016-0582). All patients who provided tissue samples agreed to donate their specimens and provided written informed consents.

$R N A$ extraction and RT-PCR. We isolated total RNA from human livers and liver cancer cells using QIAzol reagent (Qiagen). We homogenized the frozen tissues and liver cancer cell suspensions in QIAzol reagent. The homogenates
Table II. Sequences of Primers used in the study.

\begin{tabular}{|c|c|}
\hline Gene & Primer sequence \\
\hline \multirow[t]{2}{*}{ Adora1 } & Forward 5'-TGCACTGGCCTGTTCTGTAG-3' \\
\hline & Reverse 5'-CTGCCTCTCCCACGTACAAT-3' \\
\hline \multirow[t]{2}{*}{ Adora2a } & Forward 5'-GGAGTTTGCCCCTTCCTAAG-3' \\
\hline & Reverse 5'-CTGCTTCCTCAGAACCCAAG-3 \\
\hline \multirow[t]{2}{*}{ Adora $2 b$} & Forward 5'-ATCTCCAGGTATCTTCTC-3' \\
\hline & Reverse 5'-GTTGGCATAATCCACACAG-3' \\
\hline \multirow[t]{2}{*}{ Adora3 } & Forward 5'-CCTGGGCATCACAATCCACT-3' \\
\hline & Reverse 5'-ACCCTCTTGTATCTGACGGTA-3 \\
\hline \multirow[t]{2}{*}{ Gapdh } & Forward 5'-GAGTCAACGGATTTGGTCGT-3' \\
\hline & Reverse 5'-TTGATTTTGGAGGGATCTCG-3' \\
\hline
\end{tabular}

were mixed thoroughly after adding chloroform and were centrifuged at $16,000 \mathrm{x} \mathrm{g}$ for $15 \mathrm{~min}$. The aqueous phase was removed, and the RNA was precipitated with isopropyl alcohol. RNA was pelleted, washed with $70 \%$ ethanol, dried, and eluted using DEPC-treated water. We used a spectrophotometer Nanodrop 2000 (Nanodrop) to quantify the final concentration.

We quantified transcription of relevant genes using real-time reverse transcription-polymerase chain reaction (RT-PCR) in a CFX Connect Real-Time PCR Detection System (Bio-Rad) with 5x HOT FIREPol EvaGreen qPCR Supermix (Solis BioDyne), according to the manufacturer's instructions. In brief, the samples were first denatured at $95^{\circ} \mathrm{C}$ for $15 \mathrm{~min}$, followed by 40 cycles of denaturation at $95^{\circ} \mathrm{C}$ for $15 \mathrm{sec}$, annealing at $55^{\circ} \mathrm{C}-60^{\circ} \mathrm{C}$ for $15 \mathrm{sec}$, and elongation at $72^{\circ} \mathrm{C}$ for $20 \mathrm{sec}$. The data are expressed as the fold changes in the treatment groups relative to the control level and were normalized to GAPDH levels using the delta-delta $\mathrm{Ct}$ methods (21). Table II lists the sense and antisense primer sequences.

Protein isolation and western blotting. We extracted protein samples from $\sim 2.0 \times 10^{6}$ cells or $70 \mathrm{mg}$ of frozen liver tissues. The samples were homogenized in lysis buffer (RIPA; Biosesang), quantified with BCA protein assay kit (Thermo 
A

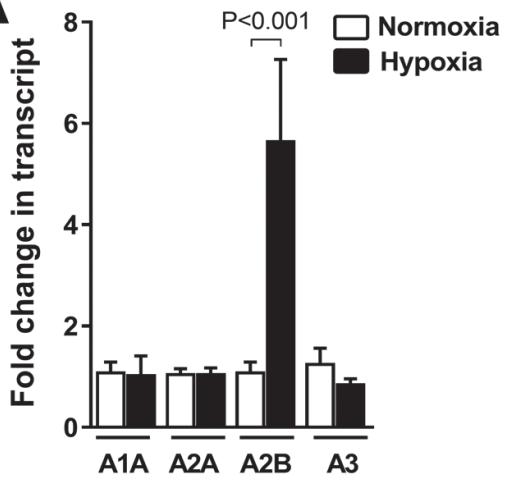

B

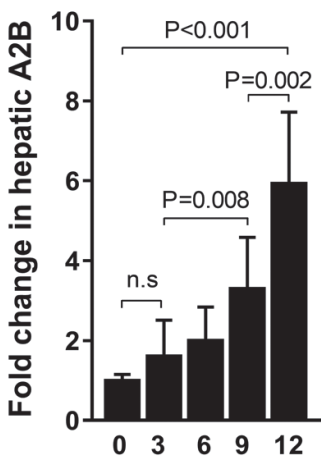

C

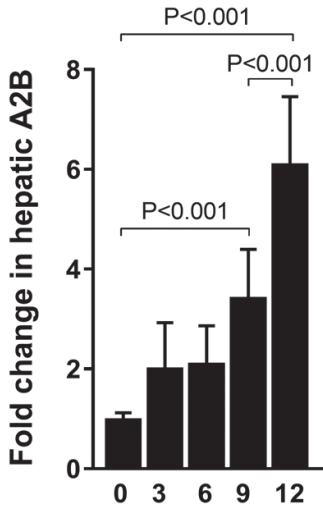

D

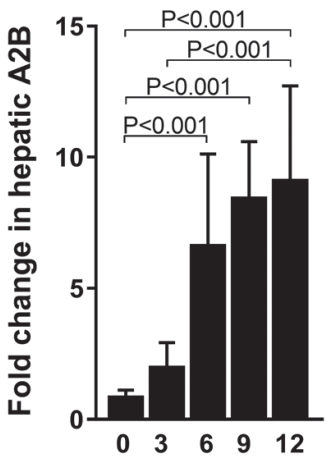

SK-Hep1 (0.5 \% oxygen) \begin{tabular}{llllll}
\hline 0 & 3 & 6 & 9 & 12 & $(\mathrm{~h})$
\end{tabular}

A2B

Actin

HepG2 ( $0.5 \%$ oxygen) $\begin{array}{lllll}0 & 3 & 6 & 9 & 12\end{array}(\mathrm{~h})$

A2B

Actin

\section{SNU449 (0.5 \% oxygen)} $\begin{array}{llllll}0 & 3 & 6 & 9 & 12 & (\mathrm{~h})\end{array}$

A2B

Actin

Figure 1. Adenosine receptor isoform expression profiles in liver cancer cell lines and A2B induction following hypoxic growth of representative liver cancer cell lines. (A) Transcript expression profiles of adenosine receptor isoforms, including A1, A2A, A2B and A3, in liver cancer cell lines (SK-Hep1, HepG2 and SNU-449). (B) Transcriptional and protein expressions of A2B in liver cancer cell lines (B) SK-HEP1, (C) HepG2 the hepatoblastoma cell line and (D) SNU-449 grown under hypoxic $\left(0.5 \% \mathrm{O}_{2}\right)$ or normal conditions. Transcriptional expression patterns and levels were detected using reverse transcription-quantitative PCR. The results were analyzed relative to GAPDH and according to fold changes relative to the control. For western blot analysis, actin was used as a loading control. Data are presented as the mean \pm standard deviation.

Fisher Scientific, Inc.), and immunoblotted with anti-adenosine A2B receptor antibody (1:1,000 dilution; ab40002, Abcam) followed by rabbit anti-goat IgG HRP (1:20,000 dilution; A5420, Sigma-Aldrich); or anti-HIF-1 $\alpha$ antibody $(1: 1,000$ dilution; cat no. 610959, BD Biosciences) followed by goat anti-mouse IgG HRP (1;5,000; sc-2005, Santa Cruz Biotechnology). We also probed the nitrocellulose membranes with actin-peroxidase conjugate (1:20,000 dilution; A3854, Sigma-Aldrich). The protein signals were detected using an enhanced chemiluminescence solution (SuperSignal ${ }^{\mathrm{TM}}$ West Femto; Thermo Fisher Scientific, Inc.), and images were obtained using the ImageQuant LAS 4000 system (GE Healthcare Biosciences).
Statistical analysis. We performed all statistical analyses using the GraphPad Prism 6.0 software (GraphPad Software). All other data are presented as the mean \pm SD. For western blot analyses, we repeated each experiment three times. We used a one-way analysis of variance (ANOVA) followed by Bonferroni's multiple comparison test. $\mathrm{P}<0.05$ was considered to indicate a statistically significant difference.

\section{Results}

Hypoxia triggered $A 2 B$ induction is time-dependent in liver cancer cells. In this study, we investigated whether A2B is upregulated under hypoxic conditions or not. Thus, we grew 
three liver cancer cell lines, SK-Hep1, HepG2, and SNU449, under hypoxic conditions. We consistently detected the significant expression of only A2B mRNA levels compared to the expression of other receptor genes (A1, A2A, and A3) under low-oxygen conditions (Fig. 1A). As shown, the A2B mRNA level and protein expressions were expressed in a time-dependent manner during hypoxia in SK-Hepl cells (Fig. 1B). Additionally, A2B is upregulated under hypoxic conditions in HepG2 (Fig. 1C) and SNU449 cells (Fig. 1D). These data reveal a selective induction of A2B during hypoxic conditions.

$H I F-1 \alpha$ directly regulated the expression of $A 2 B$ by binding to the HRE in the $A 2 B$ promoter region. To verify if $\mathrm{A} 2 \mathrm{~B}$ is transcriptionally induced by HIF-1 $\alpha$, we first searched for the human $\mathrm{A} 2 \mathrm{~B}$ promoter region, which has an HRE, containing -642 to $-647 \mathrm{bp}$, at the 5'-CACGTGG-3' sequence and its typical HIF-1 $\alpha$ ancillary HAS site (5'-CGGGGAG-3') at -546 to -541 (Fig. 2A). To investigate the function of the HIF-1 $\alpha$ binding site, we used two modified constructs, a full-length promoter construct (1095 bp) and a truncated construct (477 bp) of HIF-1 $\alpha$ (Fig. 2B). As shown in the results, the full-length HRE construct-transfected cells had significantly higher activity than the truncated construct. Next, to define whether the full-length construct was acted upon by HIF-1 $\alpha$, we performed luciferase assays with site-directed mutagenesis constructs. The mutant form of this construct had an HRE A $\underline{A T C G}$ change from ACGTG (Fig. 2C). The mutant construct (1095 Mut) exhibited low luciferase assay activity levels, as hypothesized. These results confirmed the A2B promoter region has an HRE site in it.

HIF-1 $\alpha$ upregulates $A 2 B$ expression during hypoxia. To confirm the HRE function within the promoter region of A2B, we performed experiments with HIF-1 $\alpha$ siRNA and HIF-1 $\alpha$ pcDNA plasmids. We transfected HIF-1 $\alpha$ siRNA for $12 \mathrm{~h}$ (Fig. 3A) and then exposed the cells to hypoxia for different durations of time (Fig. 3B). HIF-1 $\alpha$ siRNA-transfected cells displayed low A2B expression levels while HIF-1 $\alpha$ is being absent. In contrast, the cells overexpressing HIF-1 $\alpha$ exhibited high A2B expression levels (Fig. 3C) and hypoxia time dependency (Fig. 3D). Moreover, we treated cells with echinomycin (a cell-permeable inhibitor of HIF-1 $\alpha$-mediated gene transcription) and observed a dose-dependent decrease in the A2B mRNA and protein expression levels during low-oxygen conditions (Fig. 3E and F). Our results suggest HIF-1 $\alpha$ is a transcriptional regulator of $\mathrm{A} 2 \mathrm{~B}$.

Silencing of $A 2 B$ in liver cancer cell suppressed cell growth and proliferation. As increased expression of adenosine $\mathrm{A} 2 \mathrm{~B}$ was observed in liver cancer cells, we tested whether the direct knock-down of A2B expression could affect cell growth and proliferation in liver cancer cells. We transfected HepG2 (the hepatoblastoma cell line) cells with A2B-siRNA and maintained them for up to $96 \mathrm{~h}$. The A2B-siRNA effectively inhibited A2B expressions compared to scr-siRNA (Fig. 4A). Treatment with A2B-siRNA for 24 to $96 \mathrm{~h}$ significantly $(\mathrm{P}<0.001)$ decreased cell proliferation, as revealed by the $\mathrm{BrdU}$ assay (Fig. 4B). Similarly, the MTT assay also showed that cell growth was greatly decreased when cells were treated with
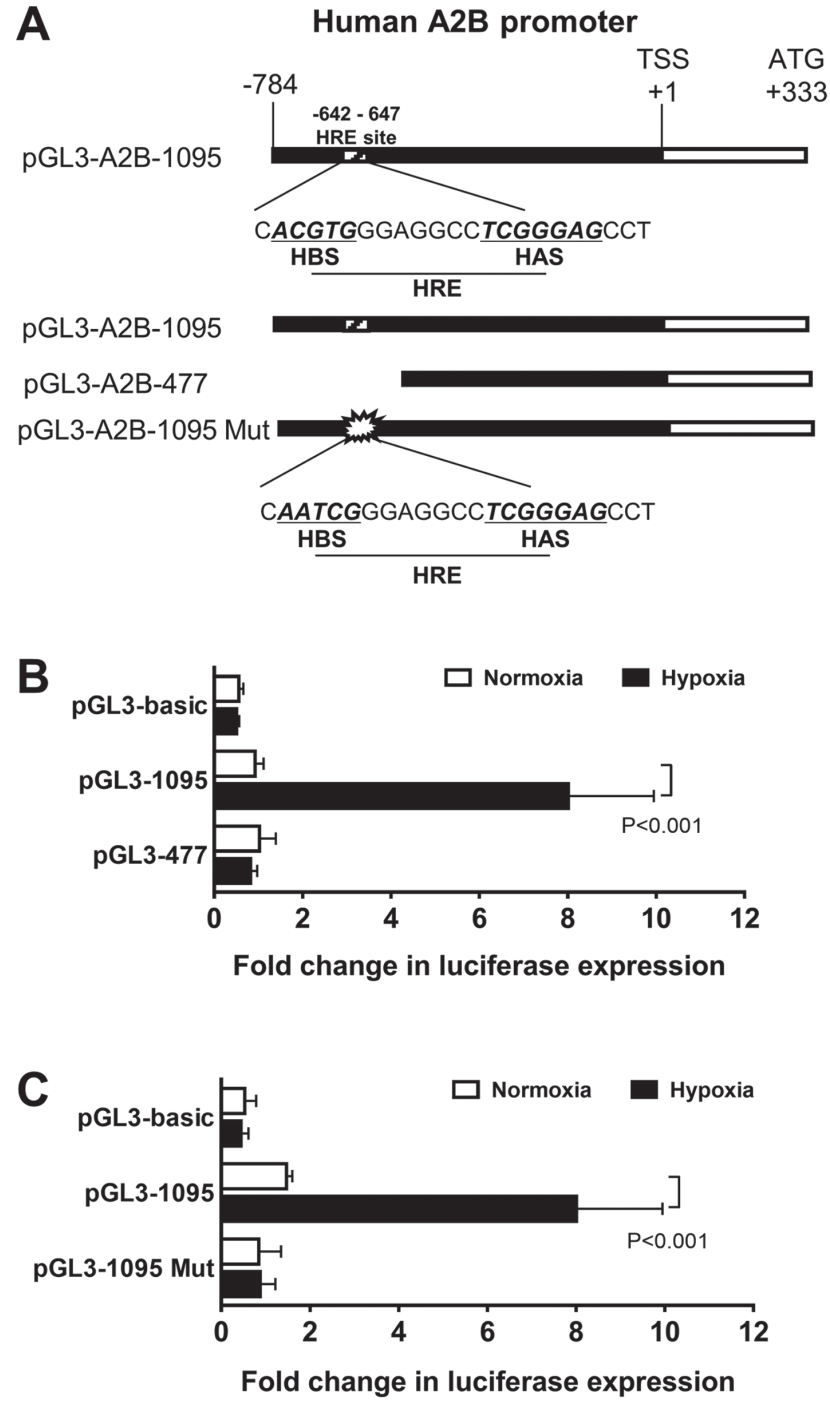

Figure 2. Luciferase reporter assays were performed to analyze A2B transcriptional activity under hypoxic conditions. (A) Map of luciferase reporter constructs indicating the position of HRE-related A2B promoter (-642 to -647). Relative positions of the HBS and HAS. (B) HepG2 cells were transfected with a full-length construct pGL3-1095 or a truncation construct pGL3-477 plasmid. The empty pGL3-basic vector was transfected as a control vector. All transfected cells were grown under $0.5 \% \mathrm{O}_{2}$ hypoxia conditions for $12 \mathrm{~h}(\mathrm{P}<0.05 ; \mathrm{n}=5)$. Renilla expression was used to normalize all luciferase expressions. (C) For site-directed mutagenesis, cells were transfected with a pGL3-1095 Mut construct and cultured under hypoxic conditions for $12 \mathrm{~h}$. The luciferase assay activity was measured and normalized with Renilla $(\mathrm{P}<0.05 ; \mathrm{n}=4)$. Data are expressed as the mean \pm standard deviation. A2B, adenosine A2B receptor; HBS, HIF binding site; HAS, HIF ancillary site; Mut, mutant.

A2B-siRNA (Fig. 4C). Additionally, the relative cell viabilities were significantly $(\mathrm{P}<0.001)$ lowered after transfection of cells with A2B-siRNA (Fig. 4D). As A2B deficient liver cancer cells show consistent decrease in cell growth and proliferation, we could conclude that A2B takes an important role in liver cancer cell proliferation.

$H I F-1 \alpha$ levels are associated with $A 2 B$ transcript and protein levels in human liver cancer specimens. Solid tumors, including liver cancer, usually experience hypoxic conditions due to the fast growth (22). To confirm the relationship between adenosine A2B receptor expression 

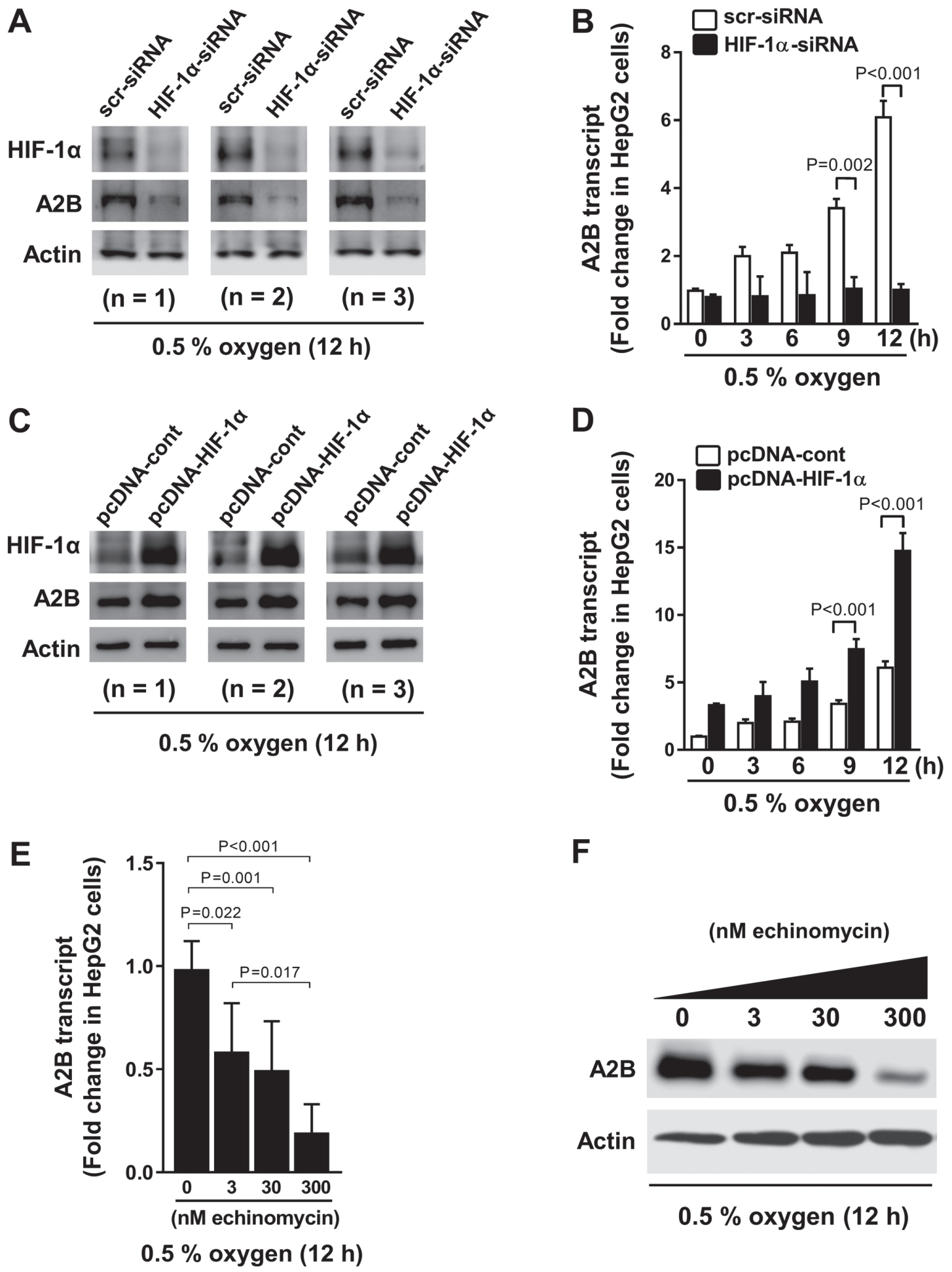

$\mathbf{F}$

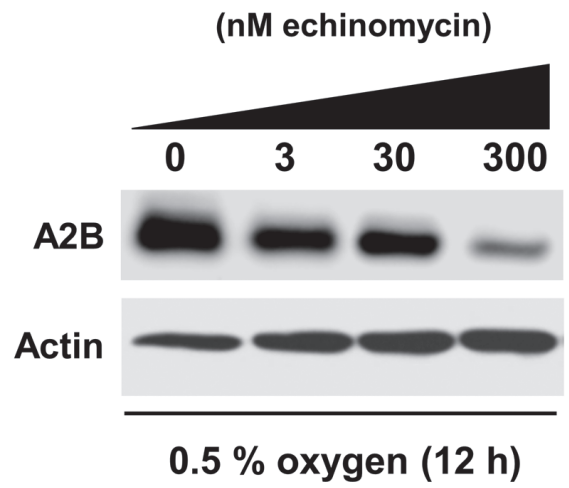

Figure 3. A2B expression profiles in liver cancer cell lines with gain- or loss- of HIF-1 $\alpha$ function under hypoxic conditions. Western blot analyses of the expression of (A) HIF-1 $\alpha$ and A2B and A2B transcript levels under hypoxic ( $0.5 \%$ oxygen) conditions for (B) up to $12 \mathrm{~h}$ in HepG2 cell lines. Cells were transfected with either scrambled-siRNA or HIF-1 $\alpha$-siRNA. Western blot analyses of (C) HIF-1 $\alpha$ and A2B expression and A2B transcript levels under hypoxic (0.5\% oxygen) conditions for (D) up to $12 \mathrm{~h}$ in HepG2 cell lines. Cells were transfected with either empty vector pcDNA3.1 (pcDNA-cont) or HIF-1 $\alpha$-pcDNA3.1 (pcDNA-HIF-1 $\alpha$ ) plasmid. (E) Cells were treated with different doses of echinomycin, a HIF-1 $\alpha$ chemical inhibitor, for (F) up to $12 \mathrm{~h}$. The expression of A2B transcript and protein levels were analyzed using RT-qPCR and western blot analysis, respectively. Data are presented as the mean \pm standard deviation $(\mathrm{n}=4)$. Actin was used as a loading control housekeeping gene for use in western blot analysis. GAPDH was used as the housekeeping gene for RT-qPCR. A2B, adenosine A2B receptor; HIF-1 $\alpha$, hypoxia inducible factor-1 $\alpha$; siRNA, small-interfering RNA; RT-q, reverse transcription-quantitative.

and human liver cancer, we tested A2B induction from both tumor tissues and the adjacent normal tissues came from identical individuals diagnosed as a liver cancer. As expected, HIF-1 $\alpha$ protein expression was high in the five human liver cancer specimens compared to its expression in normal tissues. A2B protein expression levels were also increased, suggesting that HIF-1 $\alpha$ correlates with A2B in tumors, according to the fold changes of HIF- $1 \alpha$ and A2B 
A

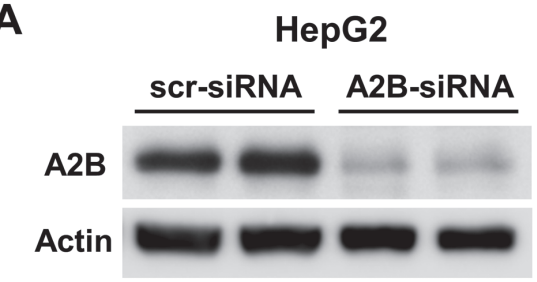

B
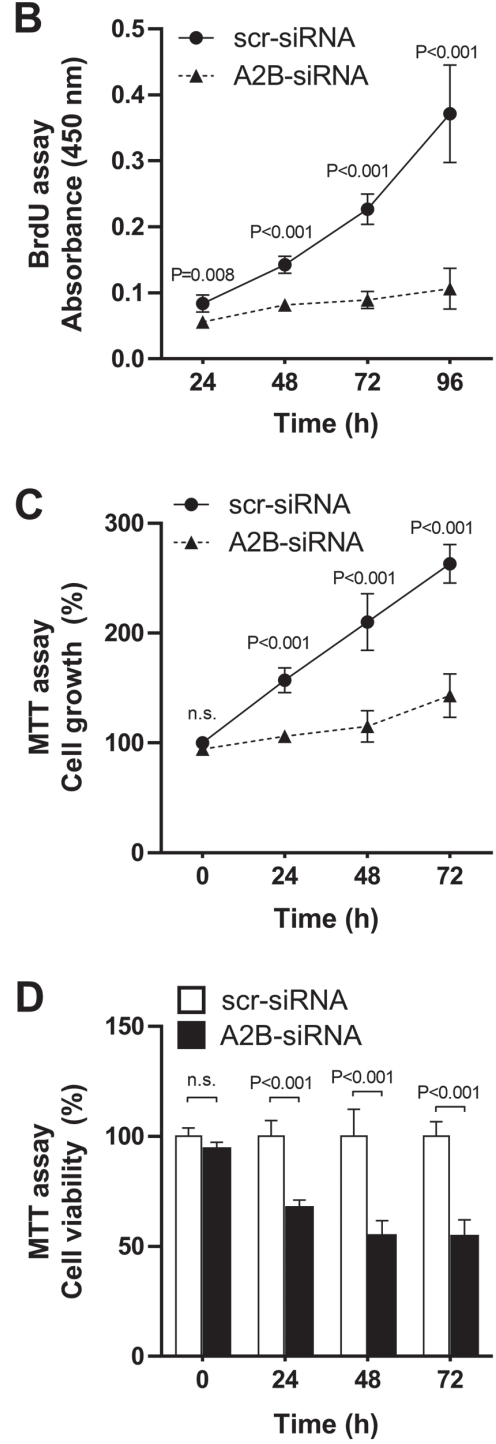

Figure 4. siRNA-mediated A2B silencing inhibits HepG2 cell proliferation. (A) HepG2 cells were transfected with either scr-siRNA or A2B-siRNA Transfection efficiency of A2B-siRNA was measured using western blot analysis. Actin was used as a loading control. (B) Cell proliferation was determined by measuring BrdU incorporation for up to $96 \mathrm{~h}(\mathrm{n}=4)$. (C) Relative cell growth rates were examined by the MTT assay. (D) Cell viability of cells at each time-point was measured by MTT assay. Data are presented as the mean \pm standard deviation $(n=4)$. Cells transfected with scr-siRNA was used as control and $\mathrm{P}<0.05$ was considered to indicate a statistically significant result. siRNA, small-interfering; A2B, adenosine A2B receptor; scr, scrambled.

densitometry results (Fig. 5A-C). Collectively, HIF-1 $\alpha$, as a master transcription factor, can bind to the A2B promoter region and induce expression of $\mathrm{A} 2 \mathrm{~B}$, thereby promoting tumor growth and survival. Moreover, we also confirmed the higher level of $\mathrm{A} 2 \mathrm{~B}$ gene expression in the HCC specimens by qRT-PCR. By contrast, we found no associations between the expression levels of mRNAs of $\mathrm{A} 1, \mathrm{~A} 2 \mathrm{~A}$, or $\mathrm{A} 3$ between normal and HCC specimens (Fig. 5D).

\section{Discussion}

In this study, we defined the various expression patterns of adenosine receptor isoforms from three different liver cancer cell lines and human liver cancer specimens. We found that the $\mathrm{A} 2 \mathrm{~B}$ expression patterns were persistently higher than those of A1, A2A, and A3 receptor subtypes in liver cancer cell lines when maintained under low-oxygen conditions. Those patterns were also observed in human liver cancers. Under the hypothesis that hypoxia-mediated HIF-1 $\alpha$ activation leads to liver cancer cell proliferation by activating adenosine $\mathrm{A} 2 \mathrm{~B}$ receptors, we followed transcription factor binding assays utilizing $\mathrm{A} 2 \mathrm{~B}$ promoter constructs and constructs with site-directed mutagenesis and have identified $\mathrm{HIF}-1 \alpha$ as the key regulator of A2B-induction during hypoxic conditions. We also investigated loss- and gain-of-function using HIF-1 $\alpha$ siRNA and overexpressing vectors. We found that the expression levels of A2B were modulated HIF-1 $\alpha$-dependently. In addition to this, echinomycin treatment dose-dependently inhibited A2B expressions under hypoxia, which indicate transcriptional induction of $\mathrm{A} 2 \mathrm{~B}$ by $\mathrm{HIF}-1 \alpha$. We also showed that active deprivation of $\mathrm{A} 2 \mathrm{~B}$ expression by siRNA suppresses cell growth and proliferation of the hepatoblastoma cell line, HepG2. Those results indicate the activation of hepatic A2B signals during low oxygen condition is related to liver cancer cell proliferation. Consistent with our in vitro results, human liver cancer specimens showed elevated levels of HIF-1 $\alpha$ along with A2B in both transcript and protein levels. These data implicate HIF-1 $\alpha$ in the regulation of adenosine-elicited cancer growth in liver.

We have previously studied the HIF-1 $\alpha$ stabilization during hypoxic conditions in liver cell lines (23) and identified the protective role of HIF- $1 \alpha$ stabilization mediated by hypoxia-induced inhibition of succinate dehydrogenase, concomitant increases in glycolytic capacity, and improved tricarboxylic acid (TCA) cycle function in alveolar epithelium (24). Also the pharmacologic studies with HIF activator or inhibitor treatment implicated HIF-1 $\alpha$-stabilization increases in liver cancer proliferation (25).

On the other hand, studies have shown the key roles of adenosine in HCC cell proliferation (26). Adenosine also upregulates endothelial cell proliferation by associating with A2B in porcine and rat arterial endothelial cells (27). In retinal endothelial cells, activated A2B can initiate neovascularization through increased angiogenic growth factor expression (28). In contrast, adenosine inhibits the growth of cardiac fibroblasts and aortic and vascular smooth muscle cells through the activation of $\mathrm{A} 2 \mathrm{~B}$, in addition to increasing the proliferation of peripheral micro-vessels, but exerts the opposite effect on cardiac tissue and capillaries (29). Thus, A2B can promote cancer proliferation and expansion by initiating neovascularization around cancer masses (30).

We showed that A2B is induced under hypoxic conditions. In general, solid cancers, such as breast, lung, colon, and prostate cancers undergo similar low-oxygen growth conditions (31); moreover, to maintain homeostasis under low-oxygen supply 

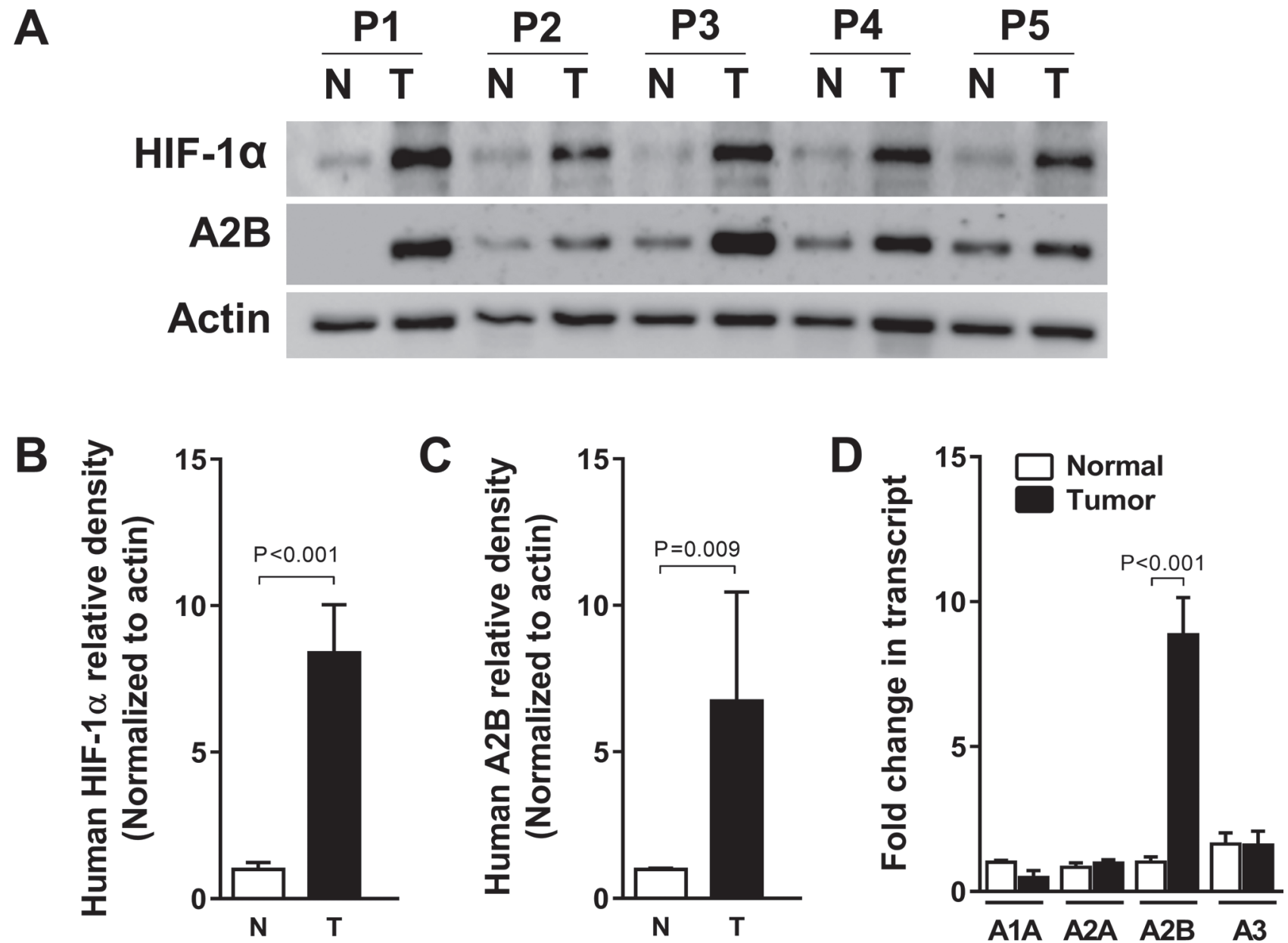

Figure 5. Protein levels of A2B and HIF-1 $\alpha$ measured in human HCC specimens and in non-cancerous tissue specimens, and mRNA levels of A2B isoforms. (A) HIF-1 $\alpha$ and A2B protein expression were detected using western blot analysis. Specimens from five patients (P1-P5) who underwent HCC hepatectomy and non-cancerous tissue specimens around the tumors. Actin was used as a loading control. Relative expression of (B) HIF-1 $\alpha$ and (C) A2B by densitometric quantification of western blots. (D) mRNA levels of A2B and other adenosine isoform receptors from five patients. The expression levels are presented relative to those of the control housekeeping gene GAPDH. The results are presented as the mean \pm standard deviation; $\mathrm{P}<0.05$; Student's t-test. A2B, adenosine A2B receptor; HIF-1 $\alpha$, hypoxia inducible factor- $1 \alpha$; HCC, hepatocellular carcinoma; T, HCC hepatectomy; N, non-cancerous tissue specimens.

conditions, specific genes need to be systematically activated and expressed or inactivated.

It was previously reported that bleomycin, a chemical irritant which induce HIF-1 $\alpha$, can mediate A2B receptor expression while inducing adenosine accumulation in acute lung injury (32). In addition, HIF-1 $\alpha$ mediated expression of A2B in endothelial cells (15), lung injury (18), breast cancer (19), and dendritic cells (33) has been reported. Nevertheless, the hypoxia mediated $\mathrm{A} 2 \mathrm{~B}$ signaling mechanism promoting liver cancer cell proliferation is yet to be elucidated.

Other researchers have suggested that adenosine receptors are highly controlled and, thus, adenosine responses might be regulated by the surface expression of adenosine receptors. Consistent with our study, Eltzschig et al reported that microarray analyses of cDNA derived from endothelial cells subjected to various periods of hypoxia revealed significant changes in the adenosine receptor's profiles, wherein the prominent phenotypic change favored A2B expression with concomitant downregulation of A1 and A2 subtypes (34). In another study, Feoktistov and Biaggioni suggested that hypoxia increases A2B expression levels releasing vascular endothelial growth factor through decreasing adenosine (35).
Human endothelial and smooth muscle cells have also been shown to express A2B (36). Moreover, hypoxia reduces matrix metalloproteinase-9 (MMP-9) production by human monocyte-derived dendritic cells and requires the activation of adenosine $\mathrm{A} 2 \mathrm{~B}$ via the $\mathrm{CAMP} /$ protein kinase (PKA) signaling pathway $(37,38)$. Collectively, these data suggest that $\mathrm{A} 2 \mathrm{~B}$ increases HIF-1 $\alpha$ dependently under hypoxic conditions and might promote liver cancer cell proliferation.

In summary, we investigated the expressions of $\mathrm{A} 2 \mathrm{~B}$ and HIF-1 $\alpha$ in liver cancer cells to find an association suggesting that under hypoxic conditions, HIF-1 $\alpha$ induces A2B expression to maintain tumor proliferation. Our results show that the upregulated $\mathrm{A} 2 \mathrm{~B}$ plays a critical role in liver cancer cell growth, suggesting $\mathrm{A} 2 \mathrm{~B}$ as a potential target for drug design; thus, an effective A2B inhibitor might be useful for treating liver cancers.

\section{Acknowledgements}

The authors would like to thank Dr Holger K. Eltzschig (University of Texas Health Science Center at Houston, TX, USA) for providing the human A2B-Luc reporter construct. 


\section{Funding}

The present study was supported by Asan Institute for Life Sciences (grant no. 15-662 and 18-IT0622), the National Research Foundation of Korea (grant no. NRF-2015K1A4A3046807), the Basic Science Research Program through the National Research Foundation of Korea funded by the Ministry of Education (grant no. NRF-2017R1D1A1B04032429) and the Yuhan Corporation (grant no. 2015-0908) and a grant of the Korea Health Technology R\&D Project through the Korea Health Industry Development Institute (KHIDI), funded by the Ministry of Health \& Welfare, Republic of Korea (grant no. HI15C0972).

\section{Availability of data and materials}

The datasets used and/or analyzed during the present study are available from the corresponding author on reasonable request.

\section{Authors' contributions}

JHK and ET designed the study. JL and JK conducted the experiments. JHK, GWS, YIY, SH, GCP and SGL performed human specimen handling. YHJ, VAK, BJK and NK contributed to the interpretation of the results. GCP and ET were involved in manuscript writing and analyzing the data. SGL, GCP and ET supervised the work. All authors provided critical feedback and conducted the research, analyzed the data and prepared the manuscript.

\section{Ethics approval and consent to participate}

The Institutional Review Board (IRB) of Asan Medical Center (Seoul, Republic of Korea) reviewed and approved the collection and use of patient specimens (approval no. 2016-0582). All patients who provided tissue samples agreed to donate their specimens and provided written informed consents.

\section{Patient consent for publication}

No applicable.

\section{Competing interests}

The authors declare that they have no competing interests.

\section{References}

1. Villanueva A: Hepatocellular carcinoma. N Engl J Med 380 1450-1462, 2019.

2. Torre LA, Siegel RL, Ward EM and Jemal A: Global cancer incidence and mortality rates and trends-an update. Cancer Epidemiol Biomarkers Prev 25: 16-27, 2016.

3. Collis MG and Hourani SM: Adenosine receptor subtypes. Trends Pharmacol Sci 14: 360-366, 1993.

4. Haskó G, Pacher P, Sylvester Vizi E and Illes P: Adenosine receptor signaling in the brain immune system. Trends Pharmacol Sci 26: 511-516, 2005.

5. Haskó G, Linden J, Cronstein B and Pacher P: Adenosine receptors: Therapeutic aspects for inflammatory and immune diseases. Nat Rev Drug Discov 7: 759-770, 2008.
6. Blay J, White TD and Hoskin DW: The extracellular fluid of solid carcinomas contains immunosuppressive concentrations of adenosine. Cancer Res 57: 2602-2605, 1997.

7. Cekic C, Sag D, Li Y, Theodorescu D, Strieter RM and Linden J: Adenosine A2B receptor blockade slows growth of bladder and breast tumors. J Immunol 188: 198-205, 2012.

8. Panjehpour M, Castro M and Klotz KN: Human breast cancer cell line MDA-MB-231 expresses endogenous A2B adenosine receptors mediating a Ca2+ signal. Br J Pharmacol 145: 211-218, 2005.

9. Ma DF, Kondo T, Nakazawa T, Niu DF, Mochizuki K, Kawasaki T, Yamane $\mathrm{T}$ and Katoh R: Hypoxia-inducible adenosine A2B receptor modulates proliferation of colon carcinoma cells. Hum Pathol 41: 1550-1557, 2010.

10. Vecchio EA, Tan CY, Gregory KJ, Christopoulos A, White PJ and May LT: Ligand-independent adenosine A2B receptor constitutive activity as a promoter of prostate cancer cell proliferation. J Pharmacol Exp Ther 357: 36-44, 2016

11. Xiang HJ, Liu ZC, Wang DS, Chen Y, Yang YL and Dou KF: Adenosine $\mathrm{A}(2 \mathrm{~b})$ receptor is highly expressed in human hepatocellular carcinoma. Hepatol Res 36: 56-60, 2006.

12. Kolachala V, Asamoah V, Wang L, Obertone TS, Ziegler TR, Merlin D and Sitaraman SV: TNF-alpha upregulates adenosine $2 \mathrm{~b}(\mathrm{~A} 2 \mathrm{~b})$ receptor expression and signaling in intestinal epithelial cells: A basis for A2bR overexpression in colitis. Cell Mol Life Sci 62: 2647-2657, 2005.

13. Xaus J, Mirabet M, Lloberas J, Soler C, Lluis C, Franco R and Celada A: IFN-gamma up-regulates the $\mathrm{A} 2 \mathrm{~B}$ adenosine receptor expression in macrophages: A mechanism of macrophage deactivation. J Immunol 162: 3607-3614, 1999.

14. Eltzschig HK, Ibla JC, Furuta GT, Leonard MO, Jacobson KA, Enjyoji K, Robson SC and Colgan SP: Coordinated adenine nucleotide phosphohydrolysis and nucleoside signaling in posthypoxic endothelium: Role of ectonucleotidases and adenosine A2B receptors. J Exp Med 198: 783-796, 2003.

15. Kong T, Westerman KA, Faigle M, Eltzschig HK and Colgan SP: HIF-dependent induction of adenosine A2B receptor in hypoxia. FASEB J 20: 2242-2250, 2006.

16. Stolze IP, Mole DR and Ratcliffe PJ: Regulation of HIF: Prolyl hydroxylases. Novartis Found Symp 272: 15-36, 2006.

17. Semenza GL: HIF-1: Upstream and downstream of cancer metabolism. Curr Opin Genet Dev 20: 51-56, 2010.

18. Eckle T, Kewley EM, Brodsky KS, Tak E, Bonney S, Gobel M, Anderson D, Glover LE, Riegel AK, Colgan SP and Eltzschig HK: Identification of hypoxia-inducible factor HIF-1A as transcriptional regulator of the $\mathrm{A} 2 \mathrm{~B}$ adenosine receptor during acute lung injury. J Immunol 192: 1249-1256, 2014.

19. Lan J, Lu H, Samanta D, Salman S, Lu Y and Semenza GL: Hypoxia-inducible factor 1-dependent expression of adenosine receptor $2 \mathrm{~B}$ promotes breast cancer stem cell enrichment. Proc Natl Acad Sci USA 115: E9640-E9648, 2018.

20. López-Terrada D, Cheung SW, Finegold MJ and Knowles BB: Hep G2 is a hepatoblastoma-derived cell line. Hum Pathol 40: $1512-1515,2009$.

21. Schmittgen TD and Livak KJ: Analyzing real-time PCR data by the comparative C (T) method. Nat Protoc 3: 1101-1108, 2008.

22. Vander Heiden MG, Cantley LC and Thompson CB: Understanding the Warburg effect: The metabolic requirements of cell proliferation. Science 324: 1029-1033, 2009.

23. Tak E, Lee S, Lee J, Rashid MA, Kim YW, Park JH, Park WS, Shokat KM, Ha J and Kim SS: Human carbonyl reductase 1 upregulated by hypoxia renders resistance to apoptosis in hepatocellular carcinoma cells. J Hepatol 54: 328-339, 2011.

24. Eckle T, Brodsky K, Bonney M, Packard T, Han J, Borchers CH, Mariani TJ, Kominsky DJ, Mittelbronn $M$ and Eltzschig HK: HIF1A reduces acute lung injury by optimizing carbohydrate metabolism in the alveolar epithelium. PLoS Biol 11: e1001665, 2013.

25. Selak MA, Armour SM, MacKenzie ED, Boulahbel H, Watson DG, Mansfield KD, Pan Y, Simon MC, Thompson CB and Gottlieb E: Succinate links TCA cycle dysfunction to oncogenesis by inhibiting HIF-alpha prolyl hydroxylase. Cancer Cell 7: 77-85, 2005.

26. Tak E, Jun DY, Kim SH, Park GC, Lee J, Hwang S, Song GW and Lee SG: Upregulation of P2Y2 nucleotide receptor in human hepatocellular carcinoma cells. J Int Med Res 44: 1234-1247, 2016.

27. Dubey RK, Gillespie DG and Jackson EK: A(2B) adenosine receptors stimulate growth of porcine and rat arterial endothelial cells. Hypertension 39: 530-535, 2002. 
28. Grant MB, Tarnuzzer RW, Caballero S, Ozeck MJ, Davis MI, Spoerri PE, Feoktistov I, Biaggioni I, Shryock JC and Belardinelli L: Adenosine receptor activation induces vascular endothelial growth factor in human retinal endothelial cells. Circ Res 85: 699-706, 1999.

29. Mustafa SJ, Morrison RR, Teng B and Pelleg A: Adenosine receptors and the heart: Role in regulation of coronary blood flow and cardiac electrophysiology. In: Adenosine Receptors in Health and Disease. Springer, pp161-188, 2009.

30. Merighi S, Mirandola P, Varani K, Gessi S, Leung E, Baraldi PG, Tabrizi MA and Borea PA: A glance at adenosine receptors: Nove target for antitumor therapy. Pharmacol Ther 100: 31-48, 2003.

31. Hockel M and Vaupel P: Tumor hypoxia: Definitions and current clinical, biologic, and molecular aspects. J Natl Cancer Inst 93 266-276, 2001

32. Volmer JB,Thompson LF andBlackburnMR: Ecto-5'-nucleotidase (CD73)-mediated adenosine production is tissue protective in a model of bleomycin-induced lung injury. J Immunol 176: 4449-4458, 2006.

33. Yang M, Ma C, Liu S, Shao Q, Gao W, Song B, Sun J, Xie Q, Zhang Y, Feng A, et al: HIF-dependent induction of adenosine receptor A2b skews human dendritic cells to a Th2-stimulating phenotype under hypoxia. Immunol Cell Biol 88: 165-171, 2010.

34. Eltzschig HK, Eckle T, Mager A, Küper N, Karcher C, Weissmuiller T, Boengler K, Schulz R, Robson SC and Colgan SP: ATP release from activated neutrophils occurs via connexin 43 and modulates adenosine-dependent endothelial cell function. Circ Res 99: 1100-1108, 2006.
35. Feoktistov I and Biaggioni I: Pharmacological characterization of adenosine A2B receptors: Studies in human mast cells co-expressing A2A and A2B adenosine receptor subtypes. Biochem Pharmacol 55: 627-633, 1998.

36. Igata M, Motoshima H, Tsuruzoe K, Kojima K, Matsumura T, Kondo T, Taguchi T, Nakamaru K, Yano M, Kukidome D, et al: Adenosine monophosphate-activated protein kinase suppresses vascular smooth muscle cell proliferation through the inhibition of cell cycle progression. Circ Res 97: 837-844, 2005.

37. Zhao P, Li XG, Yang M, Shao Q, Wang D, Liu S, Song H, Song B, Zhang Y and Qu X: Hypoxia suppresses the production of MMP-9 by human monocyte-derived dendritic cells and requires activation of adenosine receptor A2b via cAMP/PKA signaling pathway. Mol Immunol 45: 2187-2195, 2008.

38. Chen H, Koupenova M, Yang D, Sume SS, Trackman PC and Ravid K: Regulation of MMP-9 expression by the A2b adenosine receptor and its dependency on TNF- $\alpha$ signaling. Exp Hematol 39: 525-530, 2011.

This work is licensed under a Creative Commons Attribution-NonCommercial-NoDerivatives 4.0 International (CC BY-NC-ND 4.0) License. 